\title{
Comparative Efficacy of Different Pesticide Residue Mitigation Modules in Mango
}

\author{
Muhammad Asif Farooq*1, Muhammad Jalal Arif ${ }^{1}$, Muhammad Dildar Gogi ${ }^{1}$, Ahmad Nawaz $^{1}$, \\ Bilal Atta ${ }^{2}$
}

${ }^{1}$ Department of Entomology, University of Agriculture, Pakistan

${ }^{2}$ Rice Research Instiute, Kala Shah Kaku, Pakistan

*Corresponding author: Muhammad Asif Farooq, Department of Entomology, University of Agriculture, Faisalabad, Pakistan

To Cite This Article: Muhammad Asif Farooq. Comparative Efficacy of Different Pesticide Residue Mitigation Modules in Mango. Am J Biomed Sci \& Res. 2019 - 4(4). AJBSR.MS.ID.000801. DOI: 10.34297/AJBSR.2019.04.000801

Received: July 10, 2019 | Published: August 01, 2019

\begin{abstract}
A study was conducted at different locations of Multan from March 2016 to April 2017 in which 4 IPM modules were devised for mango in comparison with the control, with the focus of pesticides residues mitigation and maximum yield. Pesticides residues mitigation modules (PRMMs) were based on the IPM tactics to suppress pest population with no or minimum use insecticides. Each module was applied in an area of 1 acre of mango orchard and pest population was monitored before and after the application of the modules. After the season of the mango was completed the yield was compared of all the modules and yield loss was also calculated in terms of fruit quantity and fruit quality. It was observed that the orchard which was grown under PRMM-2 showed maximum reduction in pest population calculated as much as $92.66 \%$ followed by PRMM-1 which was accounted for $86.13 \%$ reduction in pest population. PRMM-3 reduced the pest population up-to $77.97 \%$ followed by PRMM- 4 which reduced the pest population to level of $71.43 \%$ over control. So, the best results in terms of pest reduction were observed in PRMM- 2 which included spray of pesticides along with the use of cultural, mechanical, and attract and kill methods for the mango pests. This module outperformed the chemical method by $21.23 \%$ better in terms of pest population reduction while only IPM module with no pesticides used, pest reduction was $14.7 \%$ over chemical control methods which are in common practice by most of the farmer community in the country. PRMM-2 produced $25.29 \%$ more marketable fruits in comparison of control module while PRMM-1 produced $21.17 \%$ more marketable fruits over control. In case of PRMM-3 and PRMM-4 the percentage of surplus marketable produce over control was calculated as $17.21 \%$ and $11.47 \%$ respectively.
\end{abstract}

Keywords: Mango; Pest population; Pesticides residues; Mitigation modules

\section{Introduction}

Mango is an important fruit for its economic, nutritional and aesthetic values so the mango growers applies multiple sprays for the suppression of different insect pests of this fruit [10-15]. Regardless of the results, application of insecticides brings harm to the quality of the produce I terms of pesticides residues. Integrated pest management is the best alternate for the insecticides to coup with both pest and pesticide residue problem simultaneously [1520]. Integrated pest management which commonly known as IPM is an approach which drives long term and is pooled of divergent approaches [8] such as cultural, biological and also rational chemical control methods to diminish the pest populaces to endurable levels when pest populations reach an economic threshold level (ETL) [21-24]. With the increased mobility worldwide and globalization the risk of invasion species to cross the national and international borders is ever increasing [3,5]. Integrated pest management postures slightest risks while generating determined reimburse ments with tiniest outlays $[25,26]$. Integrated pest management has been experimentally proven to be significantly more effective than the conventional methods of pest control such as biological, cultural or chemical alone [19]. Considerate and applicable use of economic verdicts is significant while dealing with the pest populations which can increase the output while minimizing the cost in terms of resources and environmental safety [24].

Economic threshold and economic injury levels are the main gears of any cost-effective integrated pest management programs [26] and are the key players in decision making for the pesticide application against any pest population [16]. For an IPM programs to be effective, stroke must be engaged once the pest population reach a precarious density in the field so that the economic injury level is not breached [6]. Several options have been discussed to increase the production with minimum use of chemicals such as pesticides [21] including biological control and also using semiochemicals (such as insect attractants and repellents) and combination of ecological, cultural and genetic strategies for pest control $[13,20]$, this combined use of different tactics evolved as an IPM module for the crops and can decrease the use of pesticides by $60 \%$ [22]. 


\section{Materials and Methods}

IPM models were based on integrated approaches of cultural, mechanical and Eco-friendly chemical control method.

\section{Sanitation}

2. Traps (mating disruption traps, visual traps, pheromone traps, pesticide treated traps)

\section{Insect pest barriers}

4. Reduced risk pesticides (Bio-Pesticides, Bio-Chemicals)

\section{Pesticide residue mitigation modules (PRMMs) for man-} go

The treatments, as detailed below, which provided the best results during 2017-18 experiments, were included in IPM trail. Five orchards, having commercial mango variety Chaunsa heavily infested with mango mealy bug, mango fruit fly and mango hopper were selected with private farmers 1 . Southern bypass, Tehsil and District Multan, 2. Moza Bosan, Tehsil and District Multan and third was Moza Behli Shareef, Hafizwala Markaz, Tehsil Jalalpur Pirwala, District Multan 4. Moza Bosan, Tehsil and District Multan 5. Moza Sangi, Tehsil and District Multan. The year round IPM practices were applied during March 2017 to February 2018 after recording the data. After treatment, the data was recorded in coming season i.e., April 2018 to 3rd week of August 2018, when the pest appears after hatching of eggs. A Randomized completely block design (RCBD) with 8 treatments including 1 control was adopted with 3 replications. The effect of these practices (detailed below) were observed through counting the population of the pests at different intervals for different pests from the trunk of trees in unit area, marked on the trunk of trees with chalk $0.46 \mathrm{~m}$ above the ground for mealy bug, number of larvae in the fruits and number of adults in the traps for fruit fly while for the mango hopper, number of nymphs and adults count per inflorescence or the 4 sweeps of net from each side of the tree and number of pest per sweep. Percent pest population reduction was calculated as:

Percent population reduction $=\left(M_{2}-M_{1}\right) / M_{1} \times 100$

Where: $\mathrm{M}_{1}=$ Average population in treatment; $\mathrm{M}_{2}=$ Average population in control

\section{Pesticide residue mitigation module PRMM-1}

PRMM-1 includes the cultural, mechanical, GF-120 and methyl euginol+ Spinosad for the suppression of mango pests and mitigation of the pesticide residues simultaneously.

\section{Cultural practices}

Cultural practices were used to collect the egg carrying female in mounds before spreading to hibernation places. For this purpose, a plastic sheet of $1.54 \mathrm{~m}$ in width and length according to the size of trunk were spread around the trunk of the trees to stop the entry of females in roots of host plant. Mounds were made on the plastic sheet around the trunk with the materials present under the tree like dried leaves, weeds, clods of mud, grass, debris and small dried branches up to $0.46 \mathrm{~m}$ high in the $1^{\text {st }}$ week of April 2018. For direct falling females as well as those females, which were searching their hibernation places four other mounds of $0.46 \times 0.46 \mathrm{~m}$ were made under the tree with the same materials in four different directions East, West, North and South away from 1.85-2.75 m of tree without plastic sheet. So, each tree has 5 mounds. These mounds were spread at the end of June 2018 after hibernation of egg carrying females. Removal of the fallen fruits from the field to stop the fruit fly emergence and re-infesting the fruits.

\section{Mechanical practices}

Only bands were applied. These bands consist of a plastic sheet and $4 \mathrm{~cm}$ grease. The trunk of the tree is plastered with mixture of mud and wet farmyard manure (1:1 ratio). It is pasted all around the trunk $26 \mathrm{~cm}$ in width from 0.46 to $0.62 \mathrm{~m}$ above the ground so that it provides an even and smooth surface for wrapping the plastic sheet, which does not allow the nymphs to crawl from underneath the band. Then plastic sheet is wrapped around the trunk on the surface pasted with mud mixture. It is tightened from the joining ends with three $1.75 \mathrm{~cm}$ iron nails (at upper, middle, lower ends of joint) with a hammer. After fully wrapping the plastic sheet a $4 \mathrm{~cm}$ grease band is applied in the middle portion of plastic sheet. This band was applied on the trunk of the trees in December-2017 to 3rd week of March 2018 to stop the upward movement of nymphs.

\section{GF-120}

GF-120 is attract and kill product of Arysta Life Sciences which includes protein hydro lysate and Spinosad. This product was used at the rate of 0.5 liters per acre after mixing with 4.5 liters of water. Solution was applied to each second trees skipping one. While in the second application the skipped trees were applied with the solution and the already sprayed ones were skipped.

\section{Methyl Euginol + Spinosad}

Methyl euginol is well known attractant for the mango fruit flies and when it was applied with insecticides such as Spinosad its controls both male and female fruit flies. A pluck of cotton was applied with 6-8 drops of methyl euginol and 3-4 drops of Spinosad and placed in the plastic traps which only allow the fruit fly to fly in but have no exit, killing the pest inside. For reducing the cost of the traps, plastic bottles of soft drinks were used as traps. The chemicals in the traps was refreshed after every 12-15 days and 6 traps were applied per acre. These traps are also available at a subsidized price from the Department of Agriculture Extension with supervised application in the field.

In the year round IPM program pheromone traps were applied in the orchards well before the emergence of fruit fly to minimize the damage and sanitation was also performed removing of dropped fruits which may host as hibernation places for the pest. A seasonal IPM was developed and field trials were performed to determine the efficacy of the traps in combination of the other IPM tactics.

\section{PRMM-2}

PRMM-2 module was developed with the sole application of IPM but with addition of the application of soft insecticide. All the IPM tactics which were used in the PRMM-1 were applied in PRMM2 and insecticide which was applied in PRMM-2 was Spinosad 
which is a product of Dow Agro-Sciences available in the market with trade name of Tracer $^{\circledR}$ and was applied at the rate of $10 \mathrm{ml}$ per acre with 100 liter of water for the solution.

\section{PRMM-3}

PRMM-3 was based on the chemical insecticides but with the additional application of the methyl euginol + Spinosad (attract and kill) a pluck of cotton was applied with 6-8 drops of methyl euginol and 3-4 drops of Spinosad and placed in the plastic traps which only allow the fruit fly to fly in but have no exit, killing the pest inside. The chemicals in the traps was refreshed after every 12-15 days and 6 traps were applied per acre. Insecticide application of Imidacloprid with the trade name of Confidor ${ }^{\circledR} 20 \%$ SL by Bayer Crop Sciences at the rate of $200 \mathrm{ml}$ with 100 liters of water for one acre of mango orchard. Bifenthrin with trade name of Jatar ${ }^{\circledR} 10 \%$ EC by Jaffar Agro-Services was applied at the rate of $20 \mathrm{ml}$ per 100 liters of water and Acetameprid at the rate of 150 gm per 100 litters of water marketed with the name of Mospilan 20 SP by Arysta Life Sciences

\section{PRMM-4}

Insecticide application of Imidacloprid with the trade name of Confidor ${ }^{\circledR} 20 \%$ SL by Bayer Crop Sciences at the rate of $200 \mathrm{ml}$ with 100 liters of water for one acre of mango orchard. Bifenthrin with trade name of Jatar ${ }^{\circledR} 10 \%$ EC by Jaffar Agro-Services was applied at the rate of $20 \mathrm{ml}$ per 100 liters of water. Trichlorofon with the trade name of Diptrex ${ }^{\circledR} 80 \%$ WP by Bayer Crop Sciences was applied at the rate of $250 \mathrm{~g}$ per 100 liters of water and Acetameprid at the rate of $150 \mathrm{gm}$ per 100 litters of water marketed with the name of Mospilan 20SP by Arysta Life Sciences for an acre of mango orchard.

\section{Control}

Orchard under the control treatment was monitored in comparison with the other 4 PRM modules for pest populations but no application of any control tactic and the damage and pest infestation was recorded. While all other inputs such as fertilizers, irrigation and farm practices were matched with other modules.

\section{Comparison of PRMMs}

The conventional and chemical modules consisted of pest suppression tactics as adopted by farmers and modules which focused on the no-chemical approach for pest control were compared for yield, marketable yield, pest infestation and reduction of pest population from all systems/modules were compared, Statistical analysis before this point.

\section{Results}

To mitigate the pesticide residues in mango 5 modules of growing mango orchards were compared named as pesticide residue mitigation module (PRMM). Each module was applied in an area of 1 acre of mango orchard and pest population was monitored before and after the application of the modules. After the season of the mango was completed the yield was compared of all the modules and yield loss was also calculated in terms of fruit quantity and fruit quality. The modules which were applied are 1) IPM which included cultural and mechanical tactics, GF-120 and methyl euginol with
Melathion as attract and kill method 2) Soft insecticide (Spinosad) along with all the tactics which were used in the first module of IPM, 3) Conventional module included all the regular practices which are being use by the farmers in the field which are in most cases insecticides and fungicide applications along with application of protein hydrolyze with Spinosad as attract and kill method and 4) Chemical method includes spray of synthetic insecticides only and all of these modules were compared with a module where no tactics were applied to suppress the pest population yet all other inputs were applied regularly as applied in other modules.

\section{Reduction in pest population}

Population of the pests in mango was closely monitored and the data was analyzed to calculate percentage of pest reduction in the four modules with comparison of control where pest population was maximum, and no control strategies were implemented. It was observed that the orchard which was grown under PRMM-2 (IPM+ soft insecticide) showed maximum reduction in pest population calculated as much as $92.66 \%$ followed by PRMM-1 (IPM) which was accounted for $86.13 \%$ reduction in pest population. PRMM-3 (insecticides plus bait) reduced the pest population up-to $77.97 \%$ followed by PRMM-4 (chemicals) which reduced the pest population to level of $71.43 \%$ over control. So, the best results in terms of pest reduction were observed in PRMM-2 which included spray of pesticides along with the use of cultural, mechanical, and attract and kill methods for the mango pests. This module outperformed the chemical method by $21.23 \%$ better in terms of pest population reduction while only IPM module with no pesticides used pest reduction was $14.7 \%$ over chemical control methods which are in common practice by most of the farmer community in the country (Table 1).

\begin{tabular}{|c|c|}
\hline \multicolumn{2}{|c|}{ Table 1: Percent reduction of pest population. } \\
\hline Module / Practices & $\begin{array}{c}\text { Population reduction (\%) over control after } \\
\text { treatment }\end{array}$ \\
\hline PRMM-1 & 86.13 \\
\hline PRMM-2 & 92.66 \\
\hline PRMM-3 & 77.97 \\
\hline PRMM-4 & 71.43 \\
\hline Control & 0 \\
\hline
\end{tabular}

\section{Pest population response to the Modules}

Pest population showed different response against modules. The maximum response showed by mango pests in PRMM- 2 (cultural + mechanical + GF-120 + methyl euginol with Melathion $\times$ Spinosad) where the population was minimum (10\%) as compared to control (52\%) and different other modules. Pest population were 14\%, 23\%, 18\% in PRMM-1 (cultural + mechanical + GF-120 + methyl euginol with Melathion), PRMM-3 (insecticides + protein hydrolyze with Spinosad) and PRMM-4 (pesticides) respectively. The results described the significance of the IPM tactics over the use of insecticides. PRMM- 2 was $42 \%$ more responsive against mango pests over control followed by PRMM-1 which was 38\% more responsive. PRMM-3 and PRMM-4 showed 34\% and 29\% more response of the pest population over control (Figure 1). 


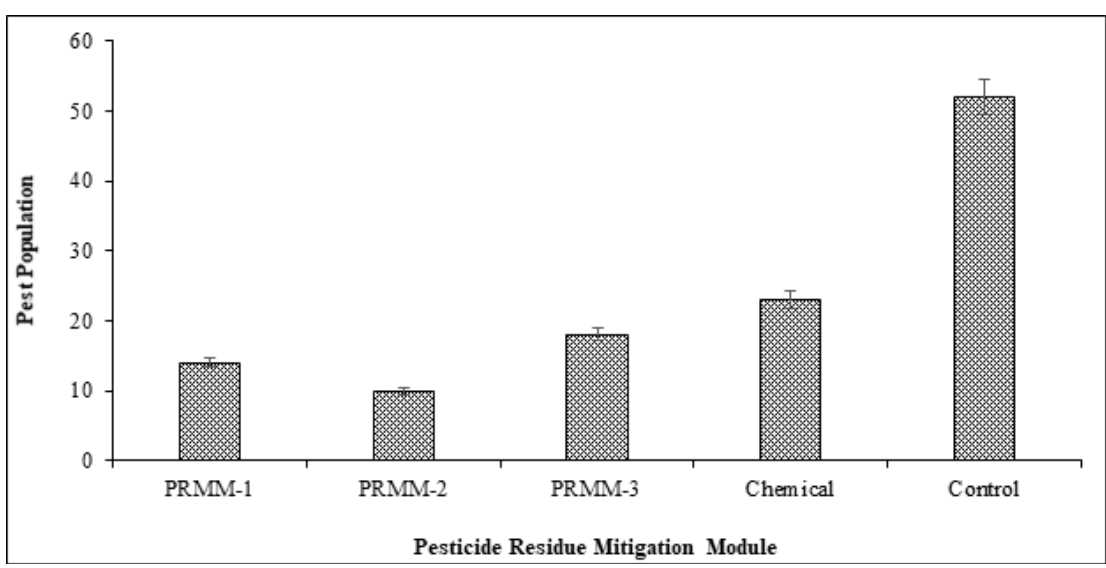

Figure 1: Response of modules to pest population.

\section{Pest Infestation}

As shown in the Figure 2 given below it was estimated that pest population was minimum in PRMM-2 where IPM was used along with soft insecticides followed by PRMM-1 where only IPM was applied as pest suppression tool. Pest infestation was calculated as $7.34 \%$ in PRMM-2 and $13.87 \%$ in PRMM-1 while pest population in PRMM-3 was recorded as much as $22.04 \%$ where synthetic pesticides were used combined with attract and kill baits. PRMM-4 received $28.57 \%$ pest infestation where only chemicals were applied. All of these modules were compared with the control module where no pest suppression tactics were applied, and pest infestation was maximum, and it was as high as $66 \%$ pest infestation.

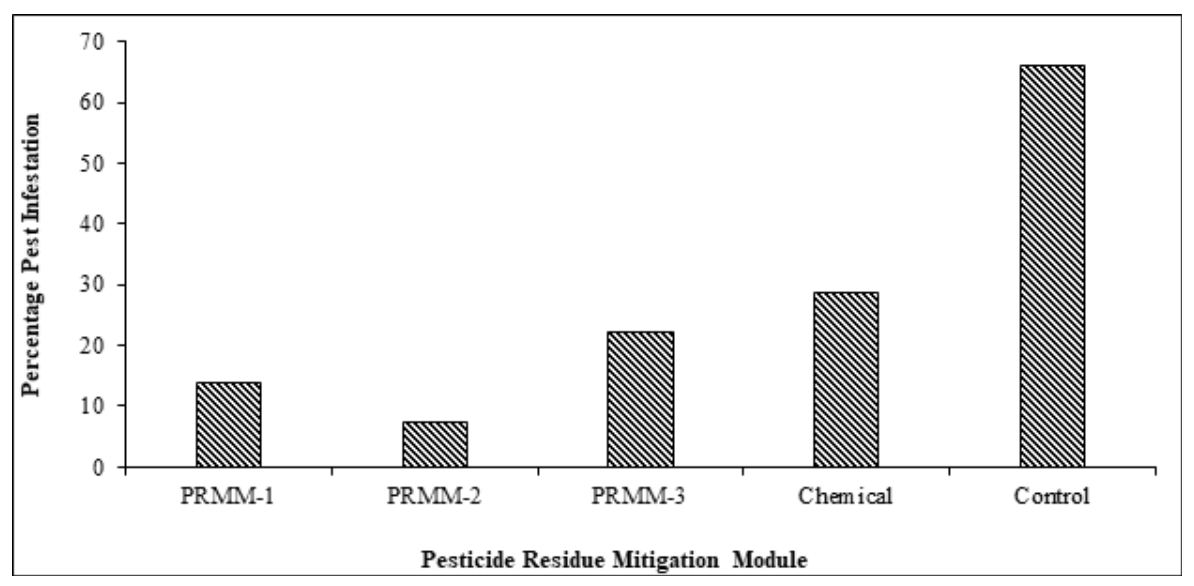

Figure 2: Response of modules to percentage pest infestation.

\section{Yield and Marketable produce comparison}

\begin{tabular}{|c|c|c|c|c|}
\hline \multicolumn{2}{|c|}{ Table 2: Yield and Marketable produce comparison } \\
\hline No & Module & Yield (Kg/Acre) & Marketable Produce (Kg/Acre) & \% Marketable Produce \\
\hline 1 & PRMM-1 (IPM) & 18341 & 14880 & 81.12 \\
\hline 2 & PRMM-2 (IPM + Spinosad) & 19106 & 16287 & 85.24 \\
\hline 3 & PRMM-3 (Conventional) & 17280 & 13473 & 77.96 \\
\hline 4 & PRMM-4 (Chemicals) & 16723 & 11945 & 71.42 \\
\hline 5 & Control & 14545 & 8720 & 59.95 \\
\hline
\end{tabular}

All the 5 modules which were applied and compared have their own benefits and draw backs in terms of yield. After the mango season was complete yield of 5 modules which were implemented was calculated and compared The loss of the produce was measured in term of quality and quantity of the fruits because not all the pests cause quantity loss such as meallybug and mango hopper but fruit fly cause quality loss of the produce. PRMM-2 gave maximum yield
$19106 \mathrm{Kg} /$ Acre from which 85.24\% was marketable yield followed by PRMM-1 with $18341 \mathrm{Kg} /$ Acre and 81.12\% marketable yield. PRMM-3 produced $17280 \mathrm{Kg} /$ Acre with $77.96 \%$ marketable fruits followed by PRMM-4 with $16723 \mathrm{Kg} /$ Acre and $71.42 \%$ marketable yield and all of these modules were compared with a control module where yield was calculated as much as $14545 \mathrm{Kg} /$ Acre while only $59.95 \%$ was marketable yield. PRMM-2 produced $25.29 \%$ 
more marketable fruits in comparison of control module while PRMM-1 produced 21.17\% more marketable fruits over control. In case of PRMM-3 and PRMM-4 the percentage of surplus marketable produce over control was calculated as $17.21 \%$ and $11.47 \%$ respectively (Table 2).

\section{Discussion}

Mango mealy bug, fruit fly and mango hopper are serious pests of mango orchards in Pakistan [10]. According to Clarke [4] achievement of pest management is judged by results and the best management technique is that which gives suitable pest control. The assessment of control measures changes in time and in space with such variables as the progress of biological understanding, changing natural circumstances, the development of technological capabilities, and differences in the thresholds of pest tolerance. However, cumulative management costs, increase of insecticide resistance, increasing environmental consciousness and growing pressure from urban development demand a more sustainable pest management system for agricultural crops [2]. Selecting an appropriate arrangement of management strategies for any pest condition, there will be some options to reflect, such as mechanical or physical control, cultural control, biological control and chemical control techniques.

The spatio-temporal separations in the life of the insect afford chances to use a range of cultural, biological and chemical control techniques alone or in combinations to control the pests in mango [9]. The present study was done to compare the efficacy of different pest management modules with sole purpose of mitigation of pesticide residues for management of mango pests focusing on mango mealy bug, mango fruit fly and mango hoper. The present study resulted that maximum reduction $(92.66 \%)$ in population of mango pests was observed in the orchard where, PRMM-2 (cultural + mechanical + GF-120 + methyl euginol with Melathion $\times$ Spinosad were applied together) followed by PRMM-1 (cultural + mechanical + GF-120 + methyl euginol with Melathion) with $86.13 \%$ pest reduction. PRMM-3 and PRMM-4 with 77.97\%, 71.43\% pest population reduction respectively. These modules showed significant difference with each other. These findings agree with the Karar et al. [11] in case of mango mealy bug population, who found that three control practices (cultural + mechanical + chemical) when combined then give maximum reduction $(98.46 \%)$ in population of mealy bug and they concluded that measures in combine form gave better results than the separate treatment as it was found in the current study.

The present findings also agree with the Bajwa and Gul [1] who found the similar results in case of mango mealy bug. Ishaq et al. [9] also worked on integrated control of mealy bug and described similar results as in present findings. He reported that this pest is difficult to manage with only water-based pesticides, so it is managed by sticky bands with burning and burying treatments, similar results were observed where PRMM-1 and PRMM-2 were applied which included cultural and mechanical tactics. The present findings also correlate with Gul et al. [7] who worked on D. stebbingi and found that banding of tree trunk, destruction of eggs and application of different insecticides are the most important control measures. PRMM-2 which included IPM and soft insecticides were applied, and maximum pest reduction was observed.

Khan and Naveed [12] worked on the population occurrence of fruit fly using the methyl euginol traps and described that maximum mean population was recorded in the month of August and it was in positive correlation to the temperature. Similar population dynamics was recorded in the present study where maximum mean population was also recoded in month of August. Patel at el. [18] described slightly better results in comparison to this study in case of fruit fly capture and kill using different kinds of baits and other IPM methods for reduction in infestation with cultural (90\%), MAT (100\%), BAT (60\%), Cover spray (50\%) and when MAT and cultural method was used in combination pest infestation was reduced to $100 \%$. In comparison of this study from India, results of the current study showed maximum reduction of pest population (92.66\%) was achieved when IPM and soft insecticides were applied in combination. Ndiaye et al. [17] from Senegal used methyl euginol, protein hydrolysate and some other homemade tarps to capture and kill the fruit fly and achieved $83 \%$ reduction of pest population and this result is slightly lower than the present study where IPM tactics achieved $86.13 \%$ reduction in pest population.

Verghese et al. [25] suppressed the population of fruit fly in mango and used combination of MAT, sanitation as cultural practice and methyl euginol and pest population was reduced to $95 \%$ in comparison of the $67 \%$ infestation in control treatment. These results are slightly different from the results of the present study where combination of sanitation, mechanical, GF-120, methyl euginol and cover spray reduced pest population to $92.66 \%$. Singh et al. [23] determined the results of the application of different IPM and chemical modules to control the fruit fly infestation in the mango orchards in India. They used MAT, baits and different chemicals and combinations of these practices and reported that the use of MAT and baits in combination can reduce the population up-to $93-95 \%$. Fruit fly infestation reduced $87-95 \%$ when these two were used along with insecticide spray and only $53-56 \%$ reduction in pest population was recorded in module where only chemical spray was used.

These results are in complete agreement of the present study where PRMM-2 reduced the pest population up-to $92.66 \%$ where IPM and insecticide were applied in combination. Kumari et al. [14] determined the results of the mango hopper population and the yield of the mango orchards after the application of 5 different chemical-based modules to suppress the pest population. They found that the best results were obtained with the three applications of Thiamethoxam, Spinosad and carbaryl at different rates of application but the yield of the individual tree was not more than $125.36 \mathrm{Kg} /$ tree while in case of the present study maximum yield with non-chemical methods was way higher than above-mentioned yield. The key difference of the two modules is the approach for only one pest (mango hopper) in comparison of all major mango pests in present study. 
Ishaq et al. [9] worked on the IPM for the control of mango mealy bug and fruit fly and use different tactics including sticky band in combination with burning and burying techniques (15.79\%), burlap bands (78.98\%), methyl euginol attract and kill traps and stem injection with $98 \%$ reduction in pest infestation. While chemical applications reduced the pest population up-to 55\%. These results are in alignment of the present study where combination of IPM tactics reduced pest population to $86.13 \%$, combine application of IPM and soft insecticide gave $92.66 \%$ reduction in pest population while methyl euginol and insecticides combined showed $77.96 \%$ and only chemical application gave $71.43 \%$ pest reduction. The difference in all the studies may be result of the approach which in this study is to suppress all the pest population of mango while in earlier described cases goal was to suppress population of a single pest.

\section{Conclusion}

Injudicious use of pesticide is a global issue for the ecosystem and sustainable agriculture posing multiple threats to non-target organisms including humans. Fruits especially mango have no exception and receives enormous amount of pesticides for pest control. In current study mitigation of pesticide residues was aimed by the use of no-chemical control tactics including soft insecticides to reach a limit of pest control acceptable for both environment and the profit seeking farmers. After the study it was concluded that use of pesticides can be minimized without compromising the level of pest control which in terms serves for better human health and clean environment. A better cropping and legislative approach to minimize injudicious use of pesticide is required.

\section{References}

1. Bajwa GA, H Gul (2000) Some observations on insect species of Paulownia species at Pakistan Forest Institute Campus, Peshawar. Pak J For 50(1-2): 71-80

2. Boavida C, P Neuenschwander, HR Herren (1995) Experimental assessment of the impact of the introduced parasitoid Gyranusoidea tebygi Noyes on the mango mealybug Rastrococcus invadens Williams by exclusion. Bio Control 5(1): 99-103.

3. Charles P, MH Williamson, S Dalmazzone (2000) The Economics of Biological Invasions. Edward Elgar Publishing ISBN 978-1-84064-378-7.

4. Clarke SR (2001) Review of the operational IPM program for the southern pine beetle. Integrated Pest Management Review 6(3-4): 293-301.

5. Clercq P, PG Mason, D Babendreier (2011) Benefits and risks of exotic biological control agents. BioControl 56(4): 681-698.

6. Grasman J, OA Van Herwaarden, L Hemerik, JC van Lenteren (2001) A two component model of host-parasitoid interactions: determination of the size of inundative releases of parasitoids in biological pest control. Math Biosci 169(2): 207-216.

7. Gul HG, A Bajwa, GN Panhwar (1997) Integrated control of mango mealy bug Drosicha stebbingi Green (Hemiptera: Margarodidae) infesting forestry tree species at the Pakistan Forest Institute, Peshawar. Pak J For 47: 65-72.

8. Hassan, Bakshi (2005) Integrated pest management: means of sustainable agricultural development in developing countries. Pak J Social sciences 3(4): 603-613.
9. Ishaq M, M Usman, M Asif, IA Khan (2004) Integrated pest management of mango against mealy bug and fruit fly. Int J Agric Biol 6: 452-454.

10. Karar H, J Arif, S Saeed, HA Sayyed (2006) A Threat to Mango. DAWN Sci-tech World.

11. Karar H, MJ Arif, HA Sayyed, S Saeed, G Abbas, M Arshad (2009) Integrated pest management of mango mealy bug (Drosicha mangiferae) in mango orchards. Int J Agric Biol 11: 81-84.

12. Khan RA, M Naveed (2017) Occurrence and Seasonal Abundance of Fruit Fly, Bactrocera zonata Saunders (Diptera: Tephritidae) in Relation to Meteorological Factors. Pak J Zool 49(3): 999-1003.

13. Khan MJ, MS Zia, M Qasim (2010) Use of pesticides and their role in environmental pollution. World Acad Sci Eng Technol 4(12): 122-128.

14. Kumari DA, V Anitha, A Girwani, CN Reddy (2014) Efficacy of various insecticidal modules against hoppers in mango. Intel J Plant Protection 7(1): 99-103.

15. Lenteren JC (2000) Measures of success in biological control of arthropods by augmentation of natural enemies, in: S Wratten, G Gurr (Eds), Measures of Success in Biological Control, Kluwer, Dordrecht.

16. Lenteren JC, J Woets (1988) Biological and integrated control in greenhouses. Annu Rev Entomol 33: 239.

17. Ndiaye M, EO Dieng, G Delhove (2008) Population dynamics and on-farm fruit fly integrated pest management in mango orchards in the natural area of niayes in Senegal. Pest Management in Horticultural Ecosystems 14(1): 1-8.

18. Patel RK, A Verghese, VM Patel, BK Joshi, JM Stonehouse, et al. (2005) Bait, lure and cultural IPM of fruit flies in mangoes in Gujarat. Pest Management in Horticultural Ecosystems 11(2): 155-158.

19. Pedigo LP (1996) Entomology and Pest Management, $2^{\text {nd }}$ edition, Prentice-Hall, Englewood Cliffs, NJ.

20. Pickett JA, ML Hamilton, AM Hooper, ZR Khan, CAO Midega (2010) Companion cropping to manage parasitic plants. Annual Review of Phytopathology 48: 161-177.

21. Pilgrim ES, CJA Macleod, MSA Blackwell (2010) Interactions amongst agricultural production and other ecosystem services delivered from European temperate grassland systems. Advances in Agronomy 109: 117-154.

22. Pretty J (2005) Sustainability in agriculture: recent progress and emergent challenges. Sustainability in agriculture Issues in Environmental Science and Technology 21: 1-15.

23. Singh, HSA Verghese, JM Stonehouse, JD Mumford, S George, G Naik, V Pandy (2008) Developing bait and lure-based integrated pest management module for mango fruit fly (Bactrocera dorsalis) management in Orissa. Indian journal of agricultural science. 78(7): 609-613.

24. Tang S, RA Cheke (2008) Models for integrated pest control and their biological implications. Mathematical Biosciences 215(1): 115-125.

25. Verghese A, K Sreedevi, DK Nagaraju (2006) Pre and post-harvest IPM for the mango fruit fly, Bactrocera dorsalis (Hendel). Proceedings of the $7^{\text {th }}$ International Symposium on Fruit Flies of Economic Importance $p$. 179-182.

26. Wright MG, MP Hoffmann, TP Kuhar, J Gardner, SA Pitcher (2005) Evaluating risks of biological control introductions: A probabilistic risk-assessment approach. Biological Control 35(3): 338-347. 